\title{
Burden of heart failure on caregivers in China: results from a cross-sectional survey
}

This article was published in the following Dove Press journal:

Drug Design, Development and Therapy

\author{
James DS Jackson' \\ Sarah E Cotton' \\ Sara Bruce Wirta ${ }^{2}$ \\ Catia C Proenca ${ }^{3}$ \\ Milun Zhang ${ }^{4}$ \\ Raquel Lahoz ${ }^{5}$ \\ Frederico J Calado 5
}

'Real World Research, Adelphi Real World, Bollington, Cheshire, UK; ${ }^{2}$ Real World Evidence Center of Excellence, Novartis Sweden AB, Stockholm, Sweden; ${ }^{3}$ Wellmera AG, Basel, Switzerland; ${ }^{4}$ Health Economics and Outcomes Research \& Access Strategy, Novartis Pharma China, Beijing, China; ${ }^{5}$ Real World Evidence Center of Excellence, Novartis Pharma AG, Basel, Switzerland
Correspondence: James DS Jackson Real World Research, Adelphi Real World, Adelphi Mill, Grimshaw Lane, Bollington, Cheshire SK 10 5JB, UK Tel +44 I625 57737 I

Fax +44I625 577294

Email james.jackson@adelphigroup.com
Purpose: Family and friends play a pivotal role in caring for patients with heart failure (HF); however, evidence of the impact of caregiving is limited. The objectives of this study were to describe the burden of caregiving on informal caregivers of patients with chronic HF in China.

Materials and methods: A cross-sectional survey of cardiologists, their patients with HF, and those patients' caregivers was conducted. Patient record forms were completed by 150 cardiologists for 10 consecutive patients. Caregivers of these patients were invited to complete a questionnaire.

Results: Overall, 458 caregivers completed a questionnaire (mean \pm standard deviation age $60.1 \pm 10.6$ years; $60 \%$ female; $77 \%$ spouses; $74 \%$ retired). Caregivers spent a mean of 24.5 (16.9) hours caregiving per week, and a third reported a reduction in their social activity, time for themselves, or time for family. Caregivers in employment took several days off work in the past 3 months owing to caregiving, sometimes resulting in reduced income. Up to $79 \%$ of caregivers reported an impact on their physical or emotional well-being, and 57\% reported deterioration in their objective health status. Inconsistencies stemming from differences in the three-level five-dimension EuroQol questionnaire and HF Caregiver Questionnaire were observed for the impact of caregiving on caregivers' health-related quality of life.

Conclusion: Assisting patients with HF is associated with caregiver burden. Addressing the needs of caregivers may help to promote their continued support and improve patient outcomes.

Keywords: burden, caregiver, China, health-related quality of life, heart failure

\section{Introduction}

Heart failure (HF) represents a major clinical and public health problem worldwide, affecting 40 million people. ${ }^{1}$ In China, there are $\sim 4.5$ million individuals with $\mathrm{HF}$, equating to a prevalence of $0.9 \%{ }^{2}$ Given the global aging population, the incidence and prevalence of HF are expected to increase significantly, ${ }^{3}$ which will likely put additional strain on health care services.

Patients with HF experience mild-to-severe impairment in their daily lives because of fatigue, shortness of breath, and other cardiac manifestations, and they often require daily support and assistance. Informal caregivers (typically family and friends) are defined as adults with significant responsibilities for the well-being of an individual diagnosed with a debilitating medical condition, who are not the patients' health care professional, ${ }^{4}$ and they play a pivotal role in the care of people living with HF. The chronic, progressive, and debilitating nature of $\mathrm{HF}$, and the fact that the patients are often elderly, means that informal caregivers are frequently required to provide highly demanding care for their loved ones, often for a decade or more resulting in significant burden for the caregivers. ${ }^{5-7}$ While being involved in care can 
be a positive experience for family members and friends, ${ }^{8}$ research also shows negative effects. The physical demands of assisting patients with HF have been shown to be associated with adverse health consequences for the caregiver; this contributes to poor emotional well-being, which in turn is an independent risk factor for increased mortality. ${ }^{9,10}$ Moreover, the emotional well-being of caregivers is positively correlated with the emotional well-being of patients with HF, as well as improvements in their condition. ${ }^{9,11}$ Thus, caring for patients with a debilitating syndrome such as HF has a health, emotional, and economic burden for the caregivers. ${ }^{12}$

Although the volume of literature on the burden of HF in China has increased in recent years, there are no data relating to the burden that HF poses specifically to caregivers, ${ }^{13}$ and most of the evidence is published in the UK and USA. ${ }^{14}$ To understand the burden that HF poses to informal caregivers caring for HF patients, we conducted a survey on caregivers that accompanied HF patients to cardiologists in the hospital setting in China.

\section{Materials and methods Study design}

Data were drawn from the Adelphi HF Disease Specific Programme, a cross-sectional survey of cardiologists, their patients with HF, and those patients' informal caregivers, conducted in a real-world setting in China in 2016. A diseasespecific program comprises three key phases: preparatory, data collection, and data processing/analysis. ${ }^{15,16}$

\section{Preparatory phase \\ Development of fieldwork materials}

Four questionnaires were developed to inform the diseasespecific program - a physician survey, a patient record form, a patient self-completion questionnaire (PSC), and a caregiver self-completion questionnaire (CSC). The physician survey was used in face-to-face interviews with cardiologists. Patient record forms were completed by the cardiologists for their patients presenting with $\mathrm{HF}$, using data from medical records. PSCs were completed by the same patients. Further information gathered from the patient record forms and PSCs has been reported by Jackson et al. ${ }^{16}$ CSCs were completed by the informal caregivers of the patients. The questionnaires were developed empirically, and their pharmacometric properties were not systematically assessed. The questionnaires were developed in English and then translated into Chinese by a local disease-specific program fieldwork agency. A second independent UK-based translation agency verified the translated materials. Samples of the questionnaires are available on request.

\section{Participant recruitment}

Cardiologists were identified from public lists of health care professionals and were invited to participate in the diseasespecific program based on predefined eligibility criteria described elsewhere. ${ }^{16}$ The first 150 cardiologists who met these criteria and who agreed to participate were enrolled. Participating cardiologists were asked to complete patient record forms for the next 10 patients they saw who presented with HF, immediately after each consultation. A quota of five patients with $\mathrm{HF}$ with reduced ejection fraction (HFrEF) and five with HF with preserved ejection fraction (HFpEF) was stipulated, but a left ventricular ejection fraction threshold was not specified. No other patient selection criteria were applied. The same patients were invited to complete PSCs at the practice, independently of their cardiologist, immediately after their consultation. One informal caregiver (only friends or family were asked to participate) of each patient was invited to complete a CSC: caregivers could complete a CSC, even if a patient for whom a patient record form was completed had not filled out a PSC. Included patients and caregivers gave consent to participate.

\section{Data collection phase}

Information on practice type was captured from the physician surveys. Information from the patient record forms included demographics and clinical characteristics; information from the PSCs covered patient demographics and their requirements for caregiver assistance. Information from the CSCs covered caregiver demographics, time spent in caregiving, activities for which the patient required daily support and which of those were most troublesome for the caregiver, impact of caregiving on employment and social life, and economic burden of caregiving. The impact of assisting patients with HF on caregivers' health-related quality of life (HRQoL) was measured using the three-level five-dimension EuroQol questionnaire (EQ-5D-3L) ${ }^{17,18}$ and the HF Caregiver Questionnaire (HF-CQ). ${ }^{19}$ The HF-CQ is a validated instrument to assess subjective outcomes of caregivers of patients with HF; it contains 21 questions covering physical, emotional/psychological, and lifestyle domains.

All responses were anonymized to preserve participant confidentiality and to avoid potential bias. The cardiologists could not see or influence the responses given by the patients or caregivers.

The survey followed the European Pharmaceutical Market Research Association guidelines. ${ }^{20}$ It is stated in the Code of Conduct that ethical approval is not necessary for this type of study, since the goal of the research is to improve understanding rather than testing hypotheses, subject to 
research being conducted in full accordance with the US Health Insurance Portability and Accountability Act 1996 and European equivalents. ${ }^{20,21}$

\section{Data processing/analysis phase}

For the purposes of analysis and interpretation, HFrEF was defined as left ventricular ejection fraction $<50 \%$ and $\mathrm{HFpEF}$ as $\geq 50 \%$ as defined in the Chinese Guidelines on HF. ${ }^{22}$ Basic descriptive statistics (such as means and proportions) were derived using the software package QPSMR Reflect Version 2007.1g (QPSMR Ltd, Wallingford, UK).

\section{Results}

\section{Study population}

The study comprised 150 cardiologists, each of whom completed patient record forms for 10 patients with HF, generating a sample of 1,500 patients. Almost two-thirds $(62 \%, n=933)$ of the patients for whom a patient record form was completed also completed a PSC, and 458 informal caregivers completed a CSC. ${ }^{16}$

\section{Cardiologist demographics}

Of the 150 cardiologists, $91 \%$ worked only in a hospital; of these, $69 \%$ worked in tier-3 hospitals.

\section{Patient and caregiver characteristics}

Overall, $55 \%$ of the patients were male, and the mean (standard deviation [SD]) age was 65.7 (10.3) years. Data on other patient characteristics have been reported by Jackson et al. ${ }^{16}$ Of the patients who answered questions about their requirement for caregiver support $(n=930), 90 \%$ were receiving assistance from an informal caregiver.

The majority (60\%) of informal caregivers were female, and their mean (SD) age was 60.1 (10.6) years (Table 1). Most caregivers (74\%) were retired or pensioners; $16 \%$ were in full-time employment. Caregivers were most commonly spouses $(77 \%)$ or a son/daughter $(20 \%)$.

\section{Burden of HF on the informal caregiver}

Time spent on caregiving and activities requiring caregiver support

Overall, caregivers had been caring for their loved ones for a mean (SD) of $1.7(2.5)$ years $(n=441)$ and spent a mean (SD) of 24.5 (16.9) hours caregiving per week $(n=350)$.

The activities for which caregivers were most often required to provide support $(n=457)$ included reminding patients to take their medication $(70 \%)$, helping patients to prepare meals $(65 \%)$, and providing emotional support and encouragement $(59 \%)$. The activities that caregivers found
Table I Caregiver demographics

\begin{tabular}{|c|c|}
\hline Demographic & n (\%) \\
\hline \multicolumn{2}{|l|}{$\operatorname{Sex}(n=458)$} \\
\hline Female & $276(60)$ \\
\hline Male & $182(40)$ \\
\hline \multicolumn{2}{|l|}{ Age (years) $(n=458)$} \\
\hline Mean (SD) & $60.1(10.6)$ \\
\hline \multicolumn{2}{|l|}{ Body mass index $\left(\mathrm{kg} / \mathrm{m}^{2}\right)(\mathrm{n}=438)$} \\
\hline Mean (SD) & $23.3(3.3)$ \\
\hline \multicolumn{2}{|l|}{ Employment status ( $\mathrm{n}=455$ ) } \\
\hline Retired/pensioner & $335(74)$ \\
\hline Working full time & $71(16)$ \\
\hline Homemaker & $34(7)$ \\
\hline Working part time & $8(2)$ \\
\hline Unemployed & $4(1)$ \\
\hline Student & $3(1)$ \\
\hline \multicolumn{2}{|l|}{ Education status $(\mathrm{n}=455)$} \\
\hline Finished mandatory education & $300(66)$ \\
\hline Undergraduate or more educated & $85(19)$ \\
\hline Did not finish mandatory education & $70(15)$ \\
\hline \multicolumn{2}{|l|}{ Relationship with the patient $(\mathrm{n}=452)$} \\
\hline Wife & $214(47)$ \\
\hline Husband & $135(30)$ \\
\hline Daughter & $45(10)$ \\
\hline Son & $43(10)$ \\
\hline Other relative & $6(1)$ \\
\hline Home help & $4(1)$ \\
\hline Other (ie, not friend, family, or home help) & $4(I)$ \\
\hline
\end{tabular}

Note: Percentages are calculated by excluding missing data and are subject to rounding.

Abbreviation: SD, standard deviation.

most troublesome $(n=403)$ were driving the patient to work, hospital, or appointments $(23 \%)$, reminding patients to take their medication $(22 \%)$, and helping with preparation of meals (14\%).

In the past 12 months, caregivers reported accompanying the patient on visits to their doctor in relation to $\mathrm{HF}$ a mean (SD) of $8.2(5.5)$ times $(n=456)$. Of the caregivers who answered the question relating to this role $(n=454)$, $47 \%$ did not live in close proximity to the hospital where the patient's care was received and on average spent just over an hour traveling to and from the hospital for each consultation $(\mathrm{n}=450)$.

\section{Impact on social life and employment}

Almost two-thirds (63\%) of caregivers reported that caregiving had resulted in changes to some aspects of their lives $(n=457)$. The largest proportion $(33 \%)$ reported a reduction in their social activities, followed by reductions in time for themselves (21\%) and time for their other family members $(12 \%)$.

At the time of consultation, almost three-quarters of informal caregivers were retired, mostly (96\%) as a result of 


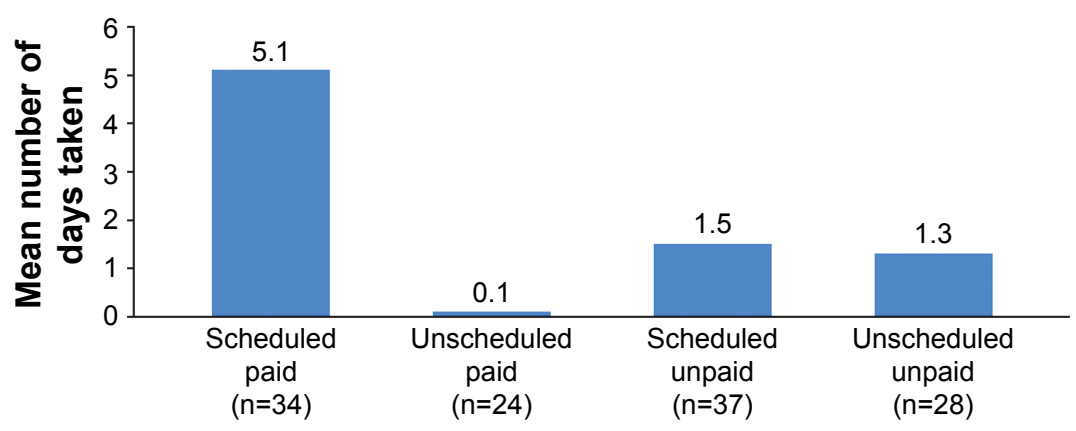

Figure I Mean number of days taken off work by caregivers in the past 3 months due to their caregiving responsibilities.

Note: Data were obtained from caregiver self-completion questionnaires.

reaching retirement age. Caregivers who had worked in the past 3 months and who answered the questions about taking time off work ( $n=24-37$ ) reported taking several days off work owing to their caregiving responsibilities (Figure 1).

\section{Impact on caregivers' own health}

More than half (57\%) of the caregivers reported that caregiving had negatively affected their health in some way $(n=446)$. The most common conditions brought on or made worse as a result of caregiving were stress $(23 \%$ of caregivers), anxiety (23\%), sleeping problems (14\%), migraines/ headaches $(9 \%)$, and depression $(7 \%)$.

On a scale of 1 (no impact) to 10 (severe impact), caregivers gave a median score (interquartile range) of 3.0 (2.0-5.0) and a mean (SD) score of 3.7 (2.0) to indicate how much their caregiving had affected their own health $(n=446)$ (Figure 2).

\section{Impact on caregivers' HRQoL}

The impact of HF on caregivers' HRQoL was measured using the EQ-5D-3L ( $n=458)$ and the HF-CQ $(n=457-458)$. Most caregivers (79\%-99\%) reported that HF had "no impact" across all the domains of HRQoL measured using the EQ-5D-3L (Table S1). In addition, the EQ-5D-3L generated a mean (SD) utility score of $0.93(0.1)$ and a score of 81.0 (9.4) on a $100 \mathrm{~mm}$ visual analog scale (the EQ-VAS). In contrast, when responding to the HF-CQ, 64\%-78\% and $56 \%-79 \%$ of caregivers reported that caregiving had compromised their physical (Figure 3) and emotional (Figure 4) well-being, respectively. In addition, $72 \%-75 \%$ caregivers reported that caregiving affected time for themselves, their ability to make or change plans, and their ability to be away from the patient (Figure 5).

\section{Economic burden of caregiving}

Most caregivers were not responsible for paying for any of the patient's HF treatment (77\%), rehabilitation (93\%), hospitalizations $(78 \%)$, or travel costs (89\%) associated with HF. However, small proportions of caregivers were personally responsible for paying for some or all of these costs (Table 2). In particular, 17\% of caregivers were responsible for paying for the patient's prescription HF drug treatment, at a mean (SD) monthly cost of $¥ 256.20$ (245.10) (\$2.31 [2.21]) (at an exchange rate of $¥ 1$ : \$0.01 on

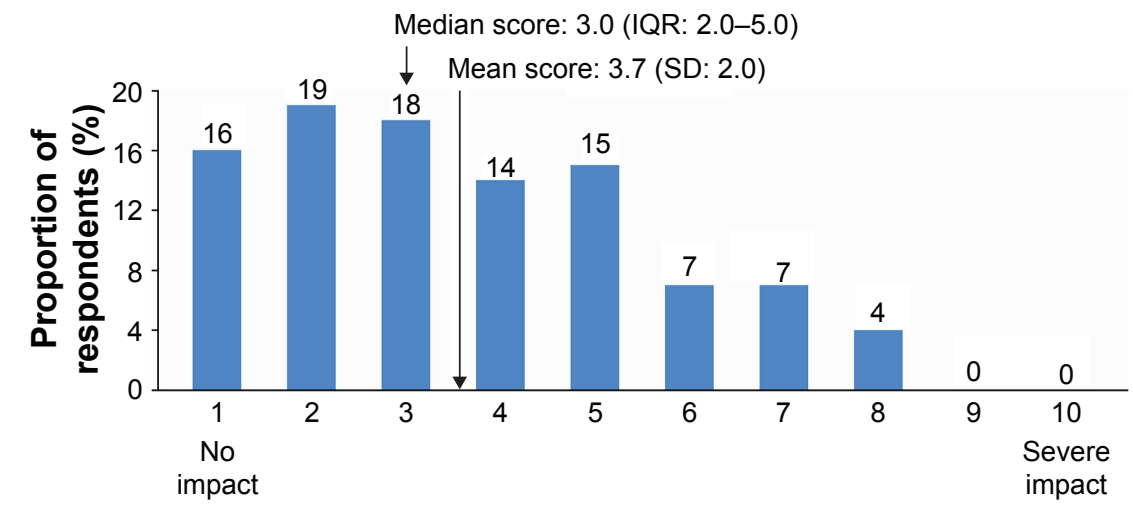

Figure 2 Impact of caregiving on caregivers' own health $(n=446)$.

Note: Data were obtained from caregiver self-completion questionnaires.

Abbreviations: IQR, interquartile range; SD, standard deviation. 


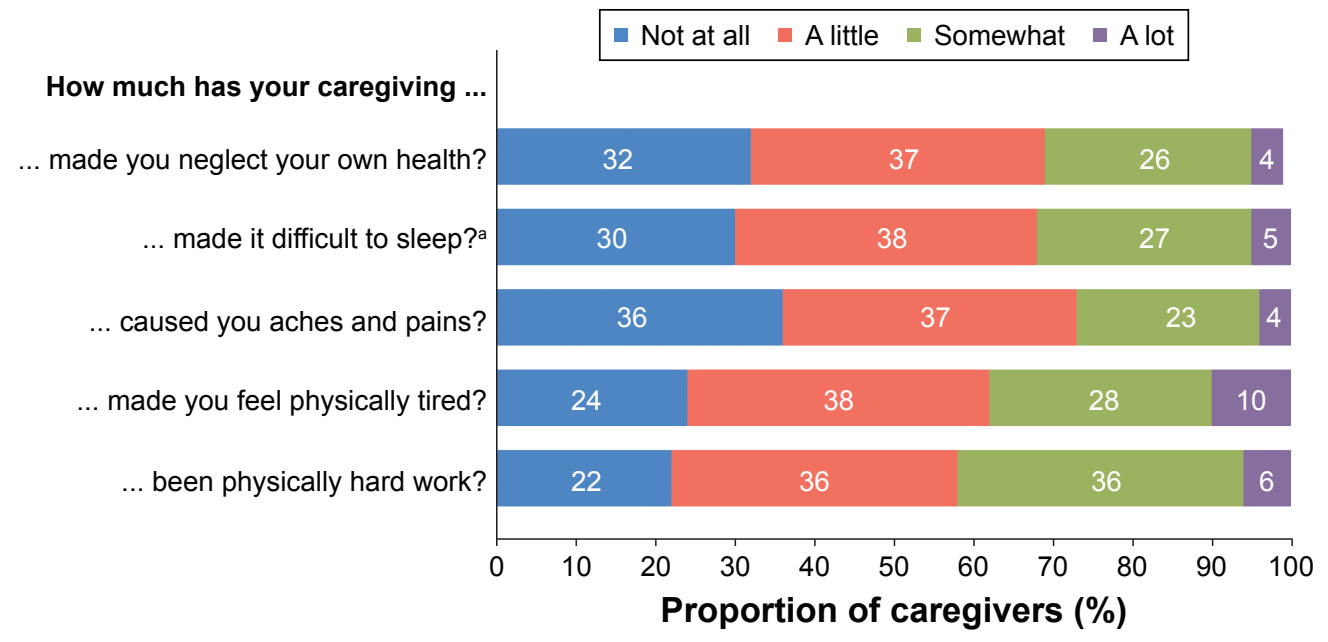

Figure 3 Impact of caring for patients with heart failure on caregivers' physical well-being over the past 4 weeks ( $\left.n=458 ;{ }^{a} n=457\right)$.

Note: Data were obtained from caregiver self-completion questionnaires.

June 12, 2017). Hospitalizations were the biggest cost, at $¥ 2496.90$ (\$22.48) per month ( $\mathrm{n}=28$ ) for caregivers paying all the cost and $¥ 3801.00$ ( $\$ 34.22$ ) for those paying some of the cost $(n=48)$.
One in five caregivers (22\%) reported that a change in their job or a reduction in working hours had resulted in a decrease in income ( $\mathrm{n}=372$ ), by a mean (SD) of $¥ 362.60$ (213.00) per month $(\$ 3.26[1.92])(n=19)$ or $18 \%(13.8 \%)(n=29)$.

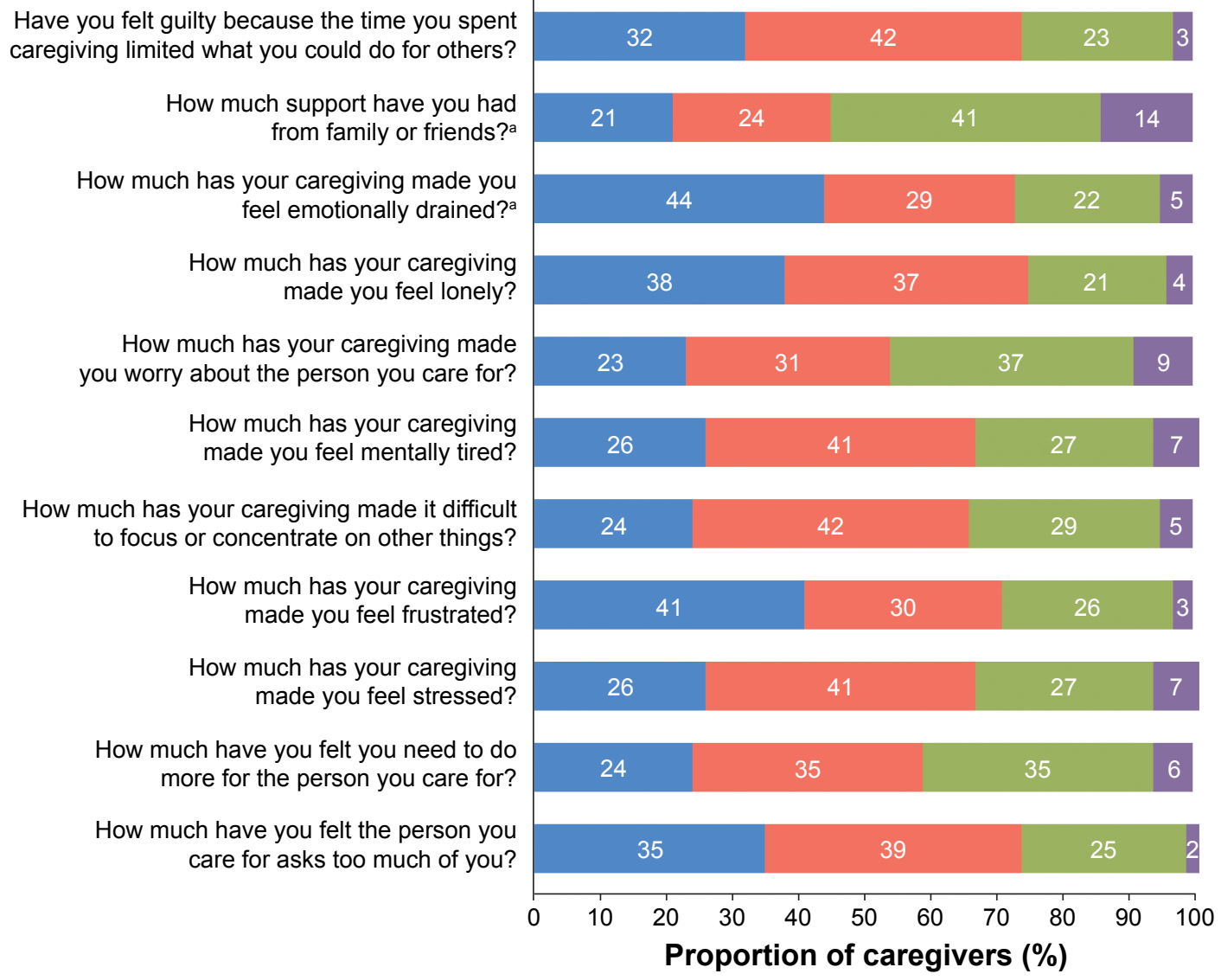

Figure 4 Impact of caring for patients with heart failure on caregivers' emotional well-being over the past 4 weeks ( $n=458$; an=457). Note: Data were obtained from caregiver self-completion questionnaires. 


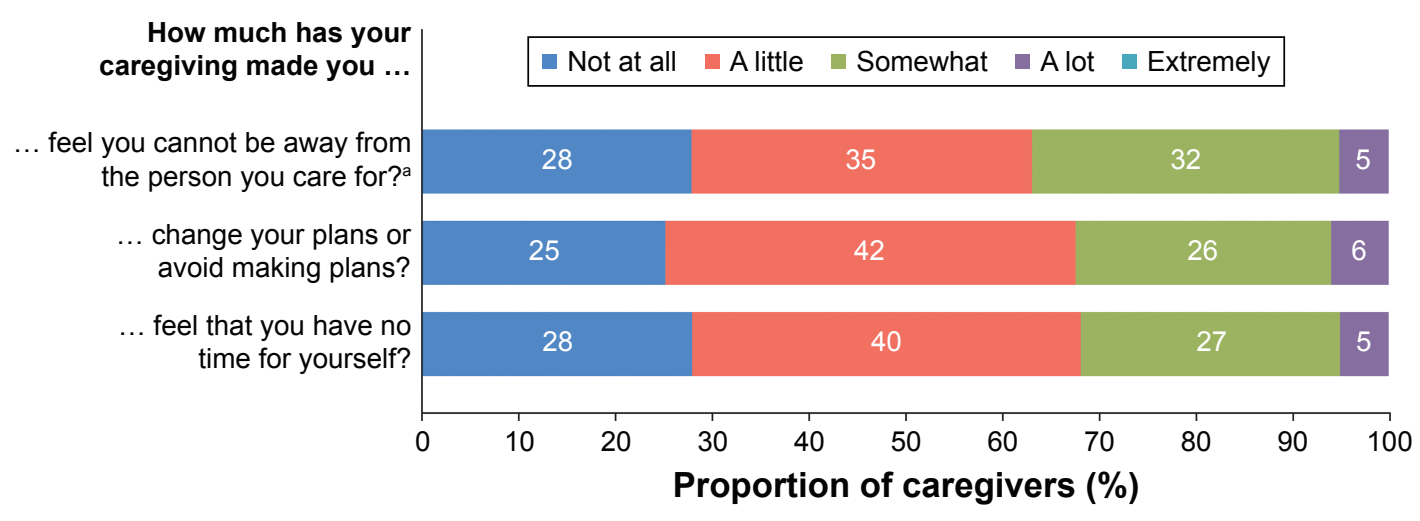

Figure 5 Impact of caring for patients with heart failure on caregivers' lifestyle over the past 4 weeks $\left(n=455\right.$; $\left.{ }^{a} n=454\right)$.

Notes: Data were obtained from caregiver self-completion questionnaires. A total of $0 \%$ responded "extremely" to this question.

Almost all caregivers (95\%) were not receiving financial support from the health care system or social services.

\section{Discussion}

Considering the central role of informal caregivers in the care of patients with HF, it is important to understand the burden of caregiving responsibilities on these individuals, in order to address their needs and promote their continued and effective support. The existing evidence is from the UK and USA $;{ }^{14}$ until now, no evidence existed on the caregiver burden of HF in China.

In the current study, an informal caregiver was typically a wife aged 60 years, in line with findings from Western

Table 2 Monthly costs associated with patients' HF that caregivers are personally responsible for

\begin{tabular}{|c|c|c|}
\hline Demographic & n (\%) & $\begin{array}{l}\text { Mean (SD) } \\
\text { monthly cost, } ¥\end{array}$ \\
\hline \multicolumn{3}{|l|}{ HF treatment $(n=455)$} \\
\hline No & $35 \mathrm{I}(77)$ & - \\
\hline Yes, prescription medicine & $78(17)$ & $256.2(245.1)^{\mathrm{a}}$ \\
\hline Yes, over the counter medicine & II (2) & $72.6(46.4)^{b}$ \\
\hline Covered by insurance policy & $22(5)$ & - \\
\hline \multicolumn{3}{|l|}{ Rehabilitation $(n=454)$} \\
\hline No & $421(93)$ & - \\
\hline Yes, all of the cost & $16(4)$ & $432.7(213.6)^{c}$ \\
\hline Yes, some of the cost & $16(4)$ & $400.0(309.0)^{d}$ \\
\hline Covered by insurance policy & $\mathrm{I}(0)$ & - \\
\hline \multicolumn{3}{|l|}{ Hospitalizations $(n=455)$} \\
\hline No & $353(78)$ & - \\
\hline Yes, all of the cost & $28(6)$ & $2,496.9(2,852.5)$ \\
\hline Yes, some of the cost & $5 I(I I)$ & $3,801.0(4,488.0)^{\mathrm{e}}$ \\
\hline Covered by insurance policy & $23(5)$ & - \\
\hline \multicolumn{3}{|l|}{ Travel costs $(n=456)$} \\
\hline No & $407(89)$ & - \\
\hline Yes, all of the cost & $34(7)$ & $181.0(208.6)$ \\
\hline Yes, some of the cost & $15(3)$ & I $55.9(244.3)$ \\
\hline
\end{tabular}

Notes: Percentages are calculated by excluding missing data and are subject to rounding. ${ }^{a} n=74 ;{ }^{b} n=10 ;{ }^{n} n=15 ;{ }^{d} n=11 ;{ }^{e} n=48$.

Abbreviations: $\mathrm{HF}$, heart failure; $\mathrm{SD}$, standard deviation. studies. ${ }^{14,23,24}$ The age of caregivers is particularly of concern because older individuals are less able than younger individuals to cope with caring for patients with chronic conditions. ${ }^{25,26}$ Indeed, up to $78 \%$ of caregivers reported that their caregiving compromised their emotional well-being, which is worrying because poor well-being and depressive symptoms may diminish the ability of caregivers to provide care for patients with HF and may thereby contribute to negative outcomes for the patients. ${ }^{7}$ Furthermore, female caregivers exhibit depressive symptoms more frequently than their male counterparts; $;^{23,24,27}$ it is therefore possible that the informal caregivers in this study may be more susceptible to poor outcomes. Caregivers spent a substantial amount of time $(\sim 25$ hours per week) assisting their loved ones; this equates to about two-thirds of the 40-hour working week stipulated by the Chinese government. ${ }^{28}$ The time spent is similar to that of professional caregivers assisting patients with HF ( $\sim 25$ hours) and longer than that of professional caregivers assisting patients who do not have an informal caregiver ( $\sim 17$ hours per week) in the current study. ${ }^{16}$ This time spent on caregiving may explain why a third of caregivers reported a reduction in their social activities, and a fifth reported having less time for themselves. Furthermore, caregivers who had worked in the past 3 months had frequently taken time off work to care for patients; in some cases, this led to a reduction in income and may have caused financial difficulty. A systematic review of caregivers' needs in advanced $\mathrm{HF}^{14}$ made similar observations. Carers of patients with HF in Western countries (mean age 54-69 years, majority wives) often had to leave employment or reduce their working hours to take on the caregiving role, which led to financial problems. ${ }^{14}$ These findings, combined with the finding that some caregivers are required to personally pay for patients' HF treatment and other associated costs, show an increased burden on caregivers. 
Finally, more than half of the caregivers reported that their responsibilities had compromised their own health, which may be because caregivers do not have time to attend to their own health. This is of particular concern, given the advanced age of the caregivers. ${ }^{29}$ Similar findings were observed in the systematic review by Doherty et al, ${ }^{14}$ which concluded that caregivers often delayed or sacrificed their own health needs to stay at home and care for their loved one. The health of caregivers and patients has been shown to be positively related; a deterioration in the health of the caregiver could therefore compromise patient outcomes. ${ }^{9}$

In the assessment of HRQoL, it is interesting that despite similar domains of HRQoL being captured in the survey and specifically by the EQ-5D-3L and HF-CQ, caregivers' responses to questions on these domains were not always consistent across the three questionnaires. When asked about the impact of caregiving on their own health, as per the survey, caregivers gave a rating of 3.7 (SD 2.0) on a scale of $1-10$ (where 10 is severely impacted); however, the EQ-5D-3L score was 0.93 (0.12) (mean [SD] EQ-VAS score 81.9 [9.4]). With regard to caregivers' emotional well-being, responses to the survey and EQ-5D-3L were similar $(23 \%$ of caregivers in the survey reported having developed [or worsened] anxiety as a result of caregiving, and $21 \%$ reported being moderately anxious or depressed in the EQ-5D-3L), whereas responses to the HF-CQ suggested that $74 \%, 59 \%$, and $74 \%$ of the caregivers had been stressed, frustrated, and/or mentally tired, respectively, in the past 4 weeks. When assessing the impact of caregiving on their lifestyle, $33 \%$ of caregivers reported a reduction in social activities as per the survey, and up to $74 \%$ reported that caring for the patient had led to changes in their own plans or to avoiding making plans as per the HF-CQ. However, with the EQ-5D-3L, only $3 \%$ of caregivers reported problems performing their usual activities (eg, work, study, housework, family, or leisure activities). The inconsistencies between responses to the EQ-5D-3L and HF-CQ could be due to the way in which the questions are posed. For example, the EQ-5D-3L asks caregivers to describe which statements best describe their situation "today," whereas the HF-CQ provides a brief definition of caregiving and asks the caregiver to think about how their caregiving has affected them in the "past 4 weeks." Furthermore, the HF-CQ specifically questions the level at which caregiving affected each domain. It is therefore possible that both the time frame and the context for each question contributed to inconsistencies in the responses. Lastly, the disease-specific nature of HF-CQ means that the burden of HF specifically to caregivers is assessed, whereas the EQ-5D can be used to assess the health status associated with a range of conditions and treatments. Disconnects between the EQ-5D and HF-CQ results were also reported in a validation study in patients with $\mathrm{HF}$ and their caregivers in the USA. ${ }^{19}$ The study found a low correlation between the two questionnaires while validating the acceptability of the HF-CQ as an instrument to measure caregiver burden due to HF. This disconnect may be explained by the fact that the HF-CQ may better capture the emotional aspects of HRQoL, with 11 items assessing this domain, compared with just one in the EQ-5D. This may also explain the high mean (SD) utility score (0.93 [0.1]) generated by the EQ-5D-3L in the current study. Although this utility score is higher than that for the patients with HF $(0.77[0.20]),{ }^{16}$ it is also higher than that for the general population aged $\geq 60$ years living in China (0.88).$^{30}$ This is unexpected because although the caregivers in this study were relatively healthy, the impact of caring for a patient with HF has been shown to compromise HRQoL. ${ }^{14}$ These findings further support those reported previously ${ }^{19}$ and suggest that the EQ-5D-3L may not be an appropriate instrument for measuring caregiver burden due to HF.

The inevitable limitations associated with data collected from surveys are relevant for the current study, including recall bias, low response rates, missing data, and overreporting of surveyed events. Nevertheless, the Adelphi Disease Specific Programmes are an established method for investigating real-world behavior and attitudes across a wide range of disease areas. ${ }^{31}$

The patients for whom caregivers were providing care in this study represent a sample of consulting patients with HF who are treated in a cardiology setting, and not those managed in primary care or by other specialities such as internal medicine or geriatricians. Only caregivers of patients receiving care in tier-2 or tier-3 hospitals were included in the current study; these are more commonly found in large cities and therefore may not reflect caregivers of patients receiving care in tier-1 hospitals, which are usually found in rural areas. Furthermore, in the current study, the split of tier-2 and tier-3 hospitals was $31 \%$ and $69 \%$, respectively, which does not reflect the split in the Chinese health care system ( $78 \%$ vs $21 \%$ ) and therefore may impact the generalizability of the data. ${ }^{32}$ The selection of patients favors inclusion of those who consult more frequently; so, patients with more severe disease or complications may be overrepresented in this sample.

Finally, some element of reporting bias may have been introduced, as the responses of caregivers of patients treated by cardiologists may have favored the specialist perspective. Nevertheless, in China, cardiologists are the specialty predominantly responsible for initial consultation, diagnosis, and 
treatment of HF. Therefore, the results of this study are likely to be representative of the current practice in China.

\section{Conclusion}

From the sample of caregivers assessed in this study, we can conclude that caring for patients with HF has a significant impact on caregivers' lives. Results of this survey revealed that caring for HF patients impacted caregivers' emotional well-being, social activities, own health, and had a psychological impact as well as a work and economic impact. Thus, when considering the overall burden that HF poses to the society, it is important to consider the indirect costs associated with a partial debilitation of caregivers. It is also important to recognize and address the pivotal role that caregivers play for the well-being of HF patients.

\section{Acknowledgments}

This study was funded by Novartis Pharma AG, Basel, Switzerland. The manuscript was developed with important intellectual input from Daniel Viriato of Novartis Pharma AG, Basel, Switzerland. Medical writing support was provided by Carly L Sellick of PharmaGenesis, London, UK, and was funded by Novartis Pharma AG, Basel, Switzerland.

\section{Disclosure}

James DS Jackson and Sarah E Cotton are employees of Adelphi Real World and were contracted by Novartis to conduct this study. Sara Bruce Wirta is an employee of Novartis Sweden AB; Raquel Lahoz and Frederico J Calado are employees of Novartis Pharma AG; and Milun Zhang is an employee of Novartis Pharma China. Catia C Proenca is an employee of Wellmera AG, contracted by Novartis Pharma AG. The authors report no other conflicts of interest in this work.

\section{References}

1. GBD 2015 Disease and Injury Incidence and Prevalence Collaborators. Global, regional, and national incidence, prevalence, and years lived with disability for 310 diseases and injuries, 1990-2015: a systematic analysis for the Global Burden of Disease Study 2015. Lancet. 2016;388(10053):1545-1602.

2. Chen WW, Gao RL, Liu LS, et al. China cardiovascular diseases report 2015: a summary. J Geriatr Cardiol. 2017;14(1):1-10.

3. National Institute for Health and Care Excellence (NICE). Chronic heart failure. Management of chronic heart failure in adults in primary and secondary care. Report no. 108. 2010. Available from: https://www.nice. org.uk/guidance/cg108. Accessed August 7, 2017.

4. Humphrey L, Kulich K, Deschaseaux C, Blackburn S, Maguire L, Stromberg A. The Caregiver Burden Questionnaire for Heart Failure (CBQ-HF): face and content validity. Health Qual Life Outcomes. 2013;11:84.

5. D'Alto M, Pacileo G, Calabro R. Nonpharmacologic care of heart failure: patient, family, and hospital organization. Am J Cardiol. 2003; 91(9A):51-54.
6. Jeon YH, Kraus SG, Jowsey T, Glasgow NJ. The experience of living with chronic heart failure: a narrative review of qualitative studies. BMC Health Serv Res. 2010;10:77.

7. Pressler SJ, Gradus-Pizlo I, Chubinski SD, et al. Family caregiver outcomes in heart failure. Am J Crit Care. 2009;18(2):149-159.

8. Hogstel MO, Curry LC, Walker C. Caring for older adults: the benefits of informal caregiving. J Theory Construct Test. 2005;9(2): $55-60$.

9. Evangelista LS, Dracup K, Doering L, Westlake C, Fonarow GC, Hamilton M. Emotional well-being of heart failure patients and their caregivers. J Card Fail. 2002;8(5):300-305.

10. Schulz R, Beach SR. Caregiving as a risk factor for mortality: the Caregiver Health Effects Study. JAMA. 1999;282(23):2215-2219.

11. Rohrbaugh MJ, Shoham V, Cleary AA, Berman JS, Ewy GA. Health consequences of partner distress in couples coping with heart failure. Heart Lung. 2009;38(4):298-305.

12. Molloy GJ, Johnston DW, Witham MD. Family caregiving and congestive heart failure. Review and analysis. Eur J Heart Fail. 2005;7(4): 592-603.

13. Hudson PL, Thomas K, Trauer T, Remedios C, Clarke D. Psychological and social profile of family caregivers on commencement of palliative care. J Pain Symptom Manage. 2011;41(3):522-534.

14. Doherty LC, Fitzsimons D, Mcllfatrick SJ. Carers' needs in advanced heart failure: a systematic narrative review. Eur J Cardiovasc Nurs. 2016; 15(4):203-212.

15. Anderson P, Benford M, Harris N, Karavali M, Piercy J. Real-world physician and patient behaviour across countries: Disease-Specific Programmes - a means to understand. Curr Med Res Opin. 2008;24(11): 3063-3072.

16. Jackson J, Cotton S, Bruce Wirta S, et al. Burden of heart failure on patients in China: results from a cross-sectional survey. Drug Des Devel Ther. 2018;12:1659-1668.

17. EuroQol Group. EuroQol - a new facility for the measurement of health-related quality of life. Health Policy. 1990;16(3):199-208.

18. Brooks R. EuroQol: the current state of play. Health Policy. 1996; 37(1):53-72.

19. Stromberg A, Bonner N, Grant L, et al. Psychometric validation of the Heart Failure Caregiver Questionnaire (HF-CQ ${ }^{\circledR}$ ). Patient. 2017; 10(5):579-592.

20. European Pharmaceutical Market Research Association (EphMRA). Code of conduct; 2017. Available from: http://www.ephmra.org/ user_uploads/ephmra\% $\% 202017 \% 20$ code $\% 20$ of $\% 20$ conduct $\% 20$ october\%202017.pdf. Accessed December 6, 2017.

21. US Department of Health \& Human Services. Summary of the HIPAA privacy rule; 2009. Available from: https://www.hhs.gov/ hipaa/for-professionals/privacy/laws-regulations/index.html. Accessed August 22, 2013.

22. Chinese Society of Cardiology of the Chinese Medical Association, Editorial Board of the Chinese Journal of Cardiology. Chinese heart failure diagnosis and treatment guidelines; 2014. Available from: http:// www.cjcv.org.cn/xinxueguan20144202/33844.htm?locale=zh_CN. Accessed August 4, 2017.

23. Ho SC, Chan A, Woo J, Chong P, Sham A. Impact of caregiving on health and quality of life: a comparative population-based study of caregivers for elderly persons and noncaregivers. J Gerontol A Biol Sci Med Sci. 2009;64(8):873-879.

24. Agren S, Evangelista L, Stromberg A. Do partners of patients with chronic heart failure experience caregiver burden? Eur J Cardiovasc Nurs. 2010;9(4):254-262.

25. Ueda T, Hashimoto M, Kurushima Y, et al. [Caregiving burden of elderly caregivers who provide at home care for infirm elderly]. Nihon Koshu Eisei Zasshi. 1994;41(6):499-506. Japanese.

26. Stensletten K, Bruvik F, Espehaug B, Drageset J. Burden of care, social support, and sense of coherence in elderly caregivers living with individuals with symptoms of dementia. Dementia (London). 2014; 15(6):1422-1435. 
27. Luttik ML, Lesman-Leegte I, Jaarsma T. Quality of life and depressive symptoms in heart failure patients and their partners: the impact of role and gender. J Card Fail. 2009;15(7):580-585.

28. State Ethnic Affairs Commission of the People's Republic of China (SEAC). [Notice on issuing measures for implementing the provisions of the state council on the working hours of staff and workers by state organizations and institutions]. 2014. Available from: http://rss.seac. gov.cn/art/2014/11/6/art_3501_218478.html. Accessed August 7, 2017. Chinese.

29. Usher BM, Cammarata K. Heart failure and family caregiver burden: an update. Prog Cardiovasc Nurs. 2009;24(3):113-114.

30. Zhang T, Shi W, Huang Z, et al. Influence of culture, residential segregation and socioeconomic development on rural elderly healthrelated quality of life in Guangxi, China. Health Qual Life Outcomes. 2016;14:98.
31. Andersohn F, Walker J. Characteristics and external validity of the German Health Risk Institute (HRI) Database. Pharmacoepidemiol Drug Saf. 2016;25(1):106-109.

32. National Health and Family Planning Commission (NHFPC). [The number of national medical and health institutions as of the end of June 2016]. Available from: http://www.nhfpc.gov.cn/mohwsbwstjxxzx/s7967/201608/87343c7d63ce41ca8d8fddf7a5db66b7.shtml. Accessed August 4, 2017. Chinese. 


\section{Supplementary materials}

Table SI Responses of caregivers to the EQ-5D-3L

\begin{tabular}{|c|c|}
\hline EQ-5D-3L domain ${ }^{1,2}$ & n (\%) \\
\hline \multicolumn{2}{|l|}{ Mobility $(n=458)$} \\
\hline I have no problems in walking about & $450(98)$ \\
\hline I have some problems walking about & $8(2)$ \\
\hline I am confined to bed & $0(0)$ \\
\hline \multicolumn{2}{|l|}{ Self-care $(n=458)$} \\
\hline I have no problems with self-care & $453(99)$ \\
\hline I have some problems with self-care & $2(0)$ \\
\hline I am unable to wash or dress myself & $3(1)$ \\
\hline \multicolumn{2}{|l|}{ Usual activities $(n=458)$} \\
\hline I have no problems with performing my usual activities & $446(97)$ \\
\hline I have some problems with performing my usual activities & $9(2)$ \\
\hline I am unable to perform my usual activities & $3(1)$ \\
\hline \multicolumn{2}{|l|}{ Pain/discomfort $(n=458)$} \\
\hline I have no pain or discomfort & $373(81)$ \\
\hline I have moderate pain or discomfort & $85(19)$ \\
\hline I have extreme pain or discomfort & $0(0)$ \\
\hline \multicolumn{2}{|l|}{ Anxiety/depression $(n=458)$} \\
\hline I am not anxious or depressed & $360(79)$ \\
\hline I am moderately anxious or depressed & $97(2 \mathrm{I})$ \\
\hline I am extremely anxious or depressed & $\mathrm{I}(0)$ \\
\hline \multicolumn{2}{|l|}{ Utility score $(n=458)$} \\
\hline Mean (SD) & $0.93(0.1)$ \\
\hline Mean (SD) EQ-VAS score $(100 \mathrm{~mm})(\mathrm{n}=458)$ & $81.0(9.4)$ \\
\hline
\end{tabular}

Notes: Values are $\mathrm{n}(\%)$ except for EQ-VAS; percentages are calculated by excluding missing data and are subject to rounding. Data were obtained from caregiver selfcompletion questionnaires. China (Simplified Chinese)(C 201I EuroQol Group EQ-5D ${ }^{T M}$ is a trademark of the EuroQol Group.

Abbreviations: EQ-5D-3L, three-level five-dimension EuroQol questionnaire; EQ-VAS, visual analog scale of the EQ-5D; SD, standard deviation.

\section{References}

1. EuroQol Group. EuroQol - a new facility for the measurement of health-related quality of life. Health Policy. 1990;16(3):199-208.

2. Brooks R. EuroQol: the current state of play. Health Policy. 1996; 37(1):53-72.
Drug Design, Development and Therapy

\section{Publish your work in this journal}

Drug Design, Development and Therapy is an international, peerreviewed open-access journal that spans the spectrum of drug design and development through to clinical applications. Clinical outcomes, patient safety, and programs for the development and effective, safe, and sustained use of medicines are the features of the journal, which

\section{Dovepress}

has also been accepted for indexing on PubMed Central. The manuscript management system is completely online and includes a very quick and fair peer-review system, which is all easy to use. Visit http://www.dovepress.com/testimonials.php to read real quotes from published authors.

Submit your manuscript here: http://www.dovepress.com/drug-design-development-and-therapy-journal 